\title{
Properties of new cork-polymer composites: Advantages and drawbacks as compared with commercially available fibreboard materials
}

\author{
Emanuel M. Fernandes ${ }^{\mathrm{a}, \mathrm{b}, *}$, Vitor M. Correlo ${ }^{\mathrm{a}, \mathrm{b}}$, José A.M. Chagas ${ }^{\mathrm{c}}$, João F. Mano ${ }^{\mathrm{a}, \mathrm{b}}$, Rui L. Reis ${ }^{\mathrm{a}, \mathrm{b}}$ \\ a 3B's Research Group - Biomaterials, Biodegradables and Biomimetics, University of Minho, Headquarters of the European Institute of Excellence on Tissue \\ Engineering and Regenerative Medicine, AvePark, Zona Industrial da Gandra, S. Cláudio do Barco, 4806-909 Caldas das Taipas, Guimarães, Portugal \\ b ICVS/3B's - PT Government Associate Laboratory, Braga, Guimarães, Portugal \\ ${ }^{\mathrm{c}}$ Amorim Revestimentos, S.A., Rua do Ribeirinho No. 202, P.O. Box 13, 4536-907 S. Paio de Oleiros, Portugal
}

\section{A R T I C L E I N F O}

\section{Article history:}

Available online 30 June 2011

\section{Keywords:}

Water absorption

Thickness swelling

Polyolefin

Cork

Mechanical properties

Thermal properties

\begin{abstract}
A B S T R A C T
Cork powder (50 wt.\%) was mixed with polypropylene (PP) or polyethylene (PE) by pultrusion aiming to prepare cork-based composites. In a further step, samples were produced by compression moulding using the compounded composites. Bending strength, impact resistance, hardness, dimensional stability, thermal and acoustic properties of the developed cork-polymer composites (CPC) were determined and compared with commercially available products namely medium density fibreboard (MDF) and high density fibreboard (HDF). It was found that the CPC have good dimensional stability, lower water uptake, a better acoustic insulation performance and similar behaviour in terms of hardness and fire resistance when compared with both MDF and HDF. However, the mechanical strength is inferior comparing with both commercial materials based on fibres. It was also observed that addition of cork improved the flexural modulus, impact resistance and hardness on the developed CPC. Thus, the herein described CPC materials showed important characteristics to be considered as good candidates to be applied in the design of flooring and construction systems.
\end{abstract}

(c) 2011 Elsevier Ltd. All rights reserved.

\section{Introduction}

Wood polymer composites (WPC), have successfully proven their applicability in several fields, particularly in the construction sector, due to their aesthetics (similar to wood), easy processability and low maintenance costs [1]. The use of lignocellulosics materials as fillers and reinforcement with thermoplastics has been gaining acceptance in commodity plastic applications [2]. Similar to wood, cork is a natural, renewable and sustainable raw material [3-5] with an unexploited potential to be used on the development of partially or completely natural based composites [6-9].

Cork is the bark of an Oak tree known botanically as Quercus suber L. [10] which is periodically extracted from the tree, usually every nine to 12 years, depending on the culture region and is of the highest importance for the forest economy of the Southern European countries and China $[4,10]$. The cork-tree offers the advantage of being the only tree whose bark can regenerate itself after harvest, making it a truly renewable material. In terms of morphology, cork can be described as an anisotropic material with close cellular struc-

* Corresponding author at: 3B's Research Group - Biomaterials, Biodegradables and Biomimetics, University of Minho, Headquarters of the European Institute of Excellence on Tissue Engineering and Regenerative Medicine, AvePark, Zona Industrial da Gandra, S. Cláudio do Barco, 4806-909 Caldas das Taipas, Guimarães, Portugal. Tel.: +351253 510900; fax: +351253510909.

E-mail address: efernandes@dep.uminho.pt (E.M. Fernandes). ture and thin-walled cells. Furthermore, cork presents a alveolar structure similar to a honeycomb according the radial direction and in the other directions (transversally) is a isotropic material where the cells are described as rectangular prisms packed base to base in columns parallel to the radial direction of the tree $[11,12]$. A thickness of $1 \mathrm{~mm}$ corresponds about thirty layers of cells [13].

Cork can be seen as a natural composite constituted by different groups of compounds. The chemical composition includes $[4,10]$ : suberin, an aliphatic polyester, usually present in high concentrations 33-50\%; lignin, an aromatic polymer, corresponding to the second most abundant structure in cork with 13-29\%; polysaccharides, including cellulose and hemicelluloses, that are usually present at concentrations in the range of $6-25 \%$; and the extractable components at concentrations in the range $8.5-24 \%$.

The structural properties of lignocellulosic materials like cork are strongly dependent on temperature. Thermal decomposition of cork has been studied by thermogravimetry [14] and the results have shown that the mass decreases about $30 \%$ upon heating at $300{ }^{\circ} \mathrm{C}$ and less than $10 \%$ at $200{ }^{\circ} \mathrm{C}$ [15]. It was also observed that the chemical degradation starts at about $250{ }^{\circ} \mathrm{C}$, in air, indicating that cork can be heated up to $250{ }^{\circ} \mathrm{C}$ without inducing irreversible changes in its composition. Chemical methods [16,17] and scanning electron microscopy [16] were also applied and the results demonstrated that waxes and other soluble components of cork begin to decompose at ca. $150{ }^{\circ} \mathrm{C}$ and that cork is transformed into ash for 
temperatures above $450^{\circ} \mathrm{C}$. Polysaccharides are considered the most heat sensitive component of cork [18]. Mass spectroscopy [19] and ${ }^{13} \mathrm{C}$ solid-state NMR studies [17] reveal that at $400{ }^{\circ} \mathrm{C}$ cork has been transformed into coke with traces of partially decomposed suberin.

The most important sub-products resulting from cork manufacturing are different types of cork powders. Part of these powders are used as fuel on industrial furnaces, while the remaining portions are usually disposed in landfills $[20,21]$. The strategy of combining cork powder with polymeric matrixes [9,21,22], to produce composites, has received little attention by the research community. However, cork properties can provide several advantages in the development of composites containing bio-based components. Among other advantages, cork has a low density (120-240 $\mathrm{kg} \mathrm{m}^{-3}$ ), can be regarded as a hydrophobic and viscoelastic material, that possess high thermal and acoustic insulation properties, low thermal conductivity, fire resistance, aesthetic features and resistance to microbial activity $[3,4,13,23]$. Moreover, cork powder is widely available, sustainable, recyclable and of low cost.

The development of appropriated methodologies for the valorisation of this bio-based resource is of high interest [9]. In this work two melt based technologies were used to produce cork-polymer composites (CPC) materials: pultrusion to compound and obtain pellets of two different composites (cork powder + PP and cork powder + PE, in both cases a 50/50 wt.\% ratio was used) and compression moulding to produce boards with adequate characteristics to be applied as core in flooring systems, furniture and building applications. The use of a core based on CPC in alternative to the MDF could be regarded as a new type of flooring able to compete in the field of the floating floor coverings. For instance, wood-plastic composites have shown distinctly better behaviour than the MDF and natural wood after moisture exposure [24]. The growing of environmental awareness has resulted in a renewed interest in the use of natural materials with environmentally friendly characteristics [25]. Formaldehyde-based adhesives are currently used for fibreboard manufacture where the major drawback of using this resin is the presence of volatile organic compounds harmful to human health $[26,27]$.

In this study, different boards - produced using the CPC composites, the MDF and the HDF - were submitted to extensive characterization tests and the obtained results compared. The main goal was to prove and validate the potential of using the corkbased composites on the production of boards as core for floating floor coverings application. We selected to test MDF and HDF boards as control since they are the most widely used wood composites applied as building material, housing furniture and in laminated flooring [26-28].

\section{Materials and methods}

\subsection{Cork powder and fibreboard materials}

The cork powder resulting from cork processing stages such as, sanding and external operations, was collected at Amorim Revestimentos S.A. (Oleiros, Portugal) industrial facilities. The cork powder presents a particle size of $\leqslant 250 \mu \mathrm{m}$, bulk density of $157 \pm 2 \mathrm{~kg} \mathrm{~m}^{-3}$ and a humidity of $\sim 5.4 \%$. It was also used two different types of fibreboard materials as control: HDF with density of $920.3 \pm 6.7 \mathrm{~kg} \mathrm{~m}^{-3}$ and MDF with density of $822.7 \pm 2.7 \mathrm{~kg} \mathrm{~m}^{-3}$ both of them with a resin content of $8 \mathrm{wt} . \%$ and supplied by Sonae Industria SGPS, S.A. (Maia, Portugal).

\subsection{Polymeric materials}

A commercially available high density polyethylene (HMA 025), HDPE, containing a thermal stabilizer and with a MFI of $8 \mathrm{~g}$
$10 \mathrm{~min}^{-1}$ and a polypropylene homopolymer (1374 E2), PP, with a MFI of $21 \mathrm{~g} 10 \mathrm{~min}^{-1}$ were used on composites preparation. Both polymers were supplied by Exxon Mobil (Germany). More details on the properties of these polymers are reported in Table 1.

\subsection{Composites processing}

Before compounding all raw materials were dried (at $70^{\circ} \mathrm{C}$ ) over night in a vacuum oven (Binder, Germany). Before compounding the moisture content on the cork powder was $\leqslant 3 \%$. Two different cork-based composites - one consisting of cork powder with PE and other consisting of cork powder with PP (in both cases 5050 wt.\% ratio was maintained) - were compounded using an industrial pultrusion system (Palltruder PFV 250, Germany). The CPC consisting of HDPE with cork powder will be referred as PE/Cork and the one from PP and cork powder as PP/Cork.

The composites, as pellets, were further compression-moulded using a Moore hydraulic press (UK) to produce rectangular boards of $220 \times 220 \times 6 \mathrm{~mm}^{3}$. The principal processing conditions are reported in Table 2 and are similar to the ones used in previous work [9]. Flexural, impact and tensile bars were cut from these boards using a CNC machine (Roland 3D Plotter MDX-20, UK).

\subsection{Dimensional stability tests}

Aiming to study the dimensional stability of the different materials, water absorption and thickness swelling tests were conducted according the ASTM D 570 [29]. To determine the water absorption, specimens (measuring $6 \mathrm{~mm}$ in thickness, $60 \mathrm{~mm}$ wide and $90 \mathrm{~mm}$ long) from the different materials were immersed in distilled water, at $23 \pm 1{ }^{\circ} \mathrm{C}$ and atmospheric pressure, for different time periods (up to 11 days). In the end of each time period, five specimens of each material were removed, gently blotted with tissue paper to remove the excess water on the surface and immediately weighed. The water absorption was calculated according to:

Water absorption $(\%)=\frac{W_{a}-W_{b}}{W_{b}} \times 100$

where $W_{a}=$ weight of the specimen after being immersed for a certain period of time and $W_{b}=$ weight of the same specimen before immersion ( $\mathrm{g})$.

To determine thickness swelling after immersion, the thickness of each immersed specimen was measured in two different points using a digital micrometre $( \pm 0.01 \mathrm{~mm})$. The thickness swelling was calculated as follows:

Thickness swelling $(\%)=\frac{T_{2}-T_{1}}{T_{1}} \times 100$

where $T_{2}=$ thickness of the specimen after immersion and $T_{1}=$ thickness of the same specimen before immersion. Three specimens per each condition were measured.

\subsection{Warping and density}

Warping can result from an inferior product construction, wrong choice of materials or inadequate processing routes. Other reason that can cause this effect is the high moisture content in the air. After processing, CPC boards $\left(220 \times 220 \times 6 \mathrm{~mm}^{3}\right)$ obtained by compression moulding were submitted to a specific test to access the possible occurrence of warping effect. The obtained results were compared with the commercial fibreboard composites cut with the same dimensions. In Fig. 1 is shown a schematic illustration of the performed test. Fig. 1a shows the used system with a pointer $p$ with precision capability of $0.01 \mathrm{~mm}$ of displacement. Two perpendicular measurements in each board were performed according the indicated directions $a$ and $b$. At least 15 boards (in 
Table 1

Properties of the polymeric matrixes.

\begin{tabular}{|c|c|c|}
\hline Polymer matrix & Property & Value \\
\hline HDPE & $\begin{array}{l}\text { Melting temperature }\left({ }^{\circ} \mathrm{C}\right) \text { obtained by differential scanning calorimetry (DSC) } \\
\text { Melt flow index }\left(\mathrm{g} 10 \mathrm{~min}^{-1}\right) \text { at }\left(T=190^{\circ} \mathrm{C} \text {, load }=2.16 \mathrm{~kg}\right) \\
\text { Density }{ }^{\mathrm{a}}\left(\mathrm{kg} \mathrm{m}^{-3}\right)\end{array}$ & $\begin{array}{l}136.6 \\
8.27 \\
960.3\end{array}$ \\
\hline PP & $\begin{array}{l}\text { Melting temperature }\left({ }^{\circ} \mathrm{C}\right) \text { obtained by differential scanning calorimetry (DSC) } \\
\text { Melt flow index }\left(\mathrm{g} 10 \mathrm{~min}^{-1}\right) \text { at }\left(T=200^{\circ} \mathrm{C} \text {, load }=2.16 \mathrm{~kg}\right) \\
\text { Density }{ }^{\mathrm{a}}\left(\mathrm{kg} \mathrm{m}^{-3}\right)\end{array}$ & $\begin{array}{c}153.5 \\
20.86 \\
900.9\end{array}$ \\
\hline
\end{tabular}

${ }^{\text {a }}$ Density according to the standard ASTM D 792.

Table 2

Processing conditions of the cork based composite boards of $6 \mathrm{~mm}$ thickness.

\begin{tabular}{|c|c|c|c|c|c|}
\hline \multirow[t]{2}{*}{ Specimens } & \multicolumn{2}{|l|}{ Pultrusion } & \multicolumn{3}{|c|}{ Compression moulding } \\
\hline & Temperature $\left({ }^{\circ} \mathrm{C}\right)$ & Output $(\mathrm{kg} / \mathrm{h})$ & Temperature $\left({ }^{\circ} \mathrm{C}\right)$ & Pressure (MPa) & Time (min) \\
\hline PE/Cork (50-50 wt.\%) & 150 & 350 & 150 & 1.42 & 14 \\
\hline PP/Cork (50-50 wt.\%) & 170 & 350 & 170 & 1.42 & 14 \\
\hline
\end{tabular}

(a)

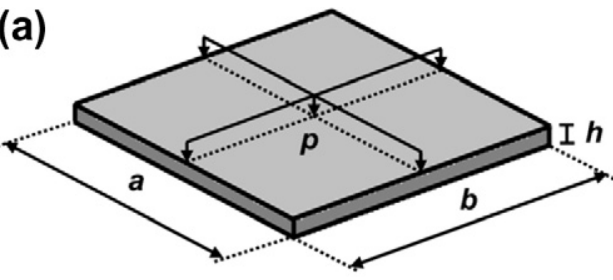

(b)

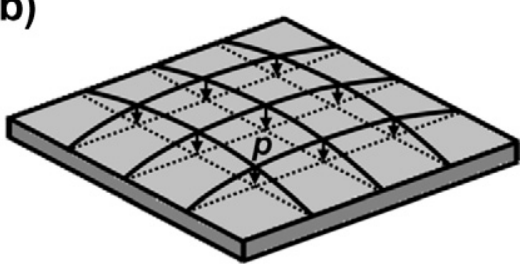

Fig. 1. Scheme of the specimen's geometry: (a) with the measuring system and (b) board with warping.

dry state) of each condition were analysed to evaluate the warping effect.

The density of the materials was determined according the ASTM D 792-00 [30], using an analytical balance equipped with a stationary support for the immersion vessel. Five specimens were weighted per each sample.

\subsection{Mechanical tests}

The mechanical properties of the developed cork-based composites were determined performing flexural and impact tests. In more detail, three point static flexural tests were carried out in accordance with standard ISO 178 [31]. The dimensions of the specimens used were $120 \mathrm{~mm}$ length, $15 \mathrm{~mm}$ width and $6 \mathrm{~mm}$ thick. The load was placed midway between the supports with a span $(L)$ of $80 \mathrm{~mm}$. The crosshead speed was $2.56 \mathrm{~mm} / \mathrm{min}$. These tested were performed in an Instron 4505 Universal Machine (USA) equipped with a $1 \mathrm{kN}$ cell load. For each condition, the specimens were loaded until the core break. The Charpy impact tests were performed according the standard ISO 179-1 [32] on a Ceast Fractovis (Pianezza, Italy) instrumented falling weight impact tester with a pendulum energy of $2 \mathrm{~J}$. The notched specimens were rectangular bars with $120 \mathrm{~mm}$ length, $12 \mathrm{~mm}$ width and $6 \mathrm{~mm}$ thick. The hardness was determined by Shore-D Hardnes Tester (model bareiss - Prüfgeräte, Germany). For each sample, the value of Shore-D was calculated as the average of 10 indentations. All performed tests were carried out in a standard laboratory atmosphere of $23{ }^{\circ} \mathrm{C}$ and $50 \%$ of relative humidity and seven specimens of each material were tested.

\subsection{Morphology}

To investigate cork distribution on the composite matrix and the fibreboard specimens, the fracture surface was analysed using a stereoscopic lens microscope Olympus SZ-PT (Tokyo, Japan) equipped with a light source Olympus Europe Highlight 2000, (Germany) and an Olympus DP11 (Japan), digital camera.

For more detailed analysis of the microstructure of the corkpolymer phases, fracture surfaces of the different specimens were examined using a NanoSEM 200 FEI (The Netherlands) scanning electron microscope (SEM). Before being analysed all the samples were coated by ion sputtering with an $\mathrm{Au} / \mathrm{Pd}$ alloy (80-20 wt.\%) in a high resolution sputter coater of Cressington 208HR(Watford, UK).

\subsection{Thermal properties}

The thermal stability studies, determined by thermogravimetric analysis (TGA) were performed to understand the degradation characteristics of the specimens using a TGA Q500 series thermogravimetric analyser (TA Instruments, USA). Experiments were performed in platinum pan, at a heating rate of $10^{\circ} \mathrm{C} \mathrm{min}^{-1}$ from $50{ }^{\circ} \mathrm{C}$ to $600{ }^{\circ} \mathrm{C}$ in air atmosphere. Analyses were performed in two samples of each condition.

\subsection{Fire resistance}

In designing building materials, fire resistance classification of the product is one of the most important features. Single flame fire tests were carried out according to the standard ISO 11925-2 [33]. The single flame source test was performed in specimens with dimensions of $188 \times 119 \mathrm{~mm}^{2}$ and $6 \mathrm{~mm}$ thick. The specimen was held vertically and a flame was applied from the bottom edge of the specimen becoming more aggressive effect on the materials. According to the standard a burning time of $15-20 \mathrm{~s}$ was applied and the burning dimensions after the test were registered. Three specimens were tested for each composite. The fire resistance classification was attributed according of the standard fire test of building materials EN ISO 13501-1 [34]. 

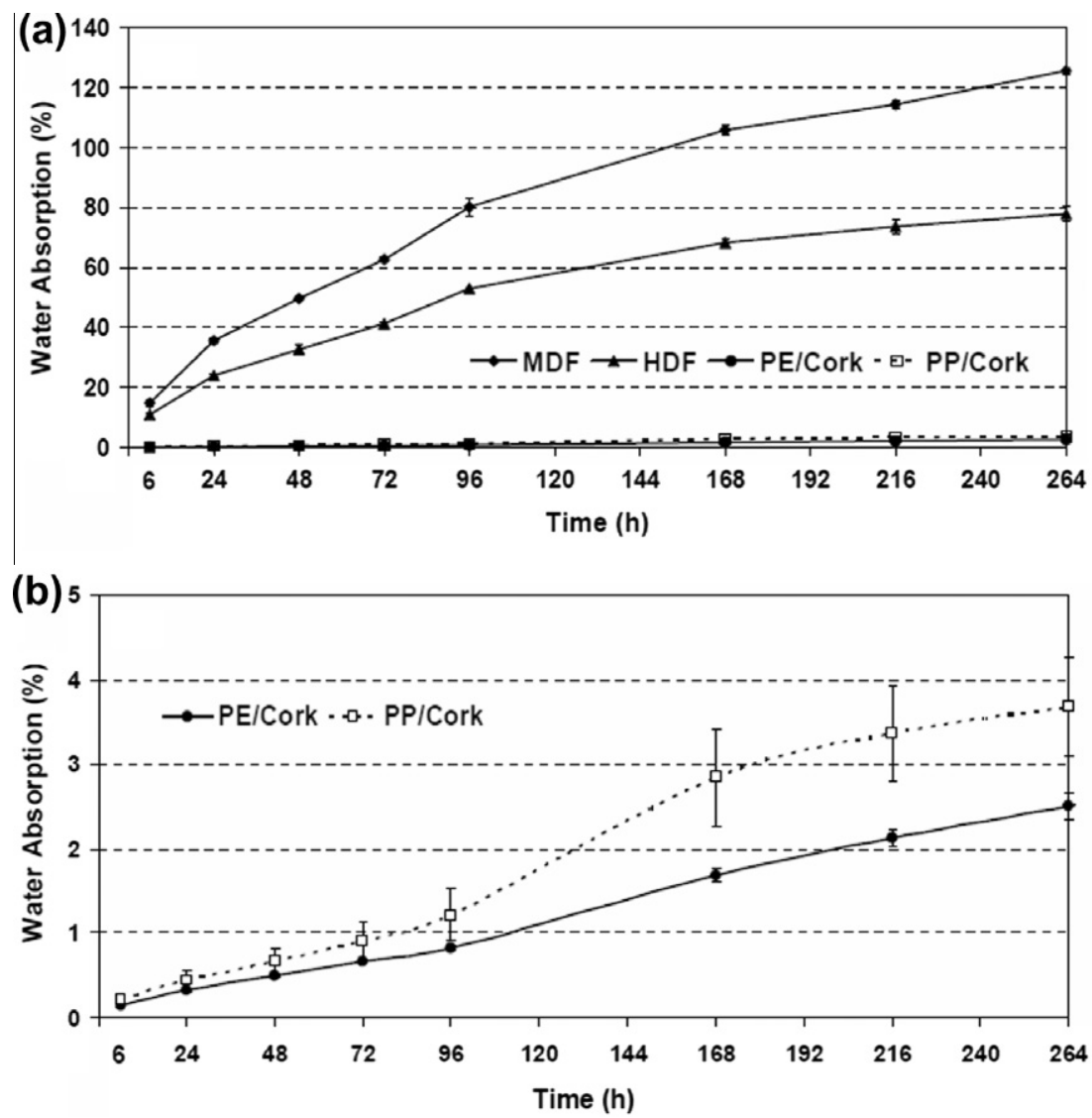

Fig. 2. Water absorption behaviour for the tested specimens during the immersion time (a) and detail of the water absorption for the cork based composites (b).

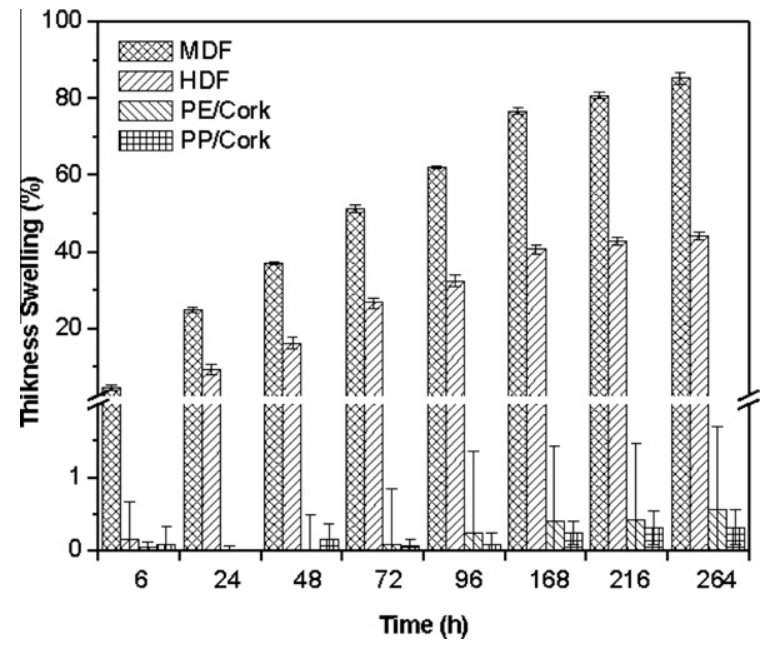

Fig. 3. Thickness swelling of the fibreboard materials and the cork based composites during the immersion tests.

\subsection{Acoustic tests}

The building elements for acoustic tests consisted on a superior element from CPC or fibreboard with dimensions of $220 \times 220 \times 6 \mathrm{~mm}^{3}$ and an agglomerated cork underlay with thickness of $1.8 \mathrm{~mm}$ thick. Commercially available silicone glue (thickness of $0.5-0.6 \mathrm{~mm}$ ) was used to fix the agglomerated cork underlay to the previously produced boards (CPC, HDF and MDF boards). The aim of including this agglomerated cork underlay was to avoid reverberation sound and fix the boards. The pavement was submitted to a uniformly distributed load $\left(20-25 \mathrm{~kg} \mathrm{~m}^{-2}\right)$. The tests were conduct in a reverberant chamber with a $7.25 \mathrm{~m}$ length, $5.88 \mathrm{~m}$ width, $4.65 \mathrm{~m}$ height and a volume of $202 \mathrm{~m}^{3}$. The tests occur at atmospheric conditions $22{ }^{\circ} \mathrm{C}$ and $66 \%$ of humidity. The equipment used for the measurements was a tapping machine Brüel \& Kjaer (B\&K, Germany) Type 3204; B\&K 2260 dual channel real-time frequency analyser and B\&K $13 \mathrm{~mm}$ microphone model 4189. The microphone height was about $1.4 \mathrm{~m}$. The measurements of sound insulation were performed according the standard EN ISO 140-8 [35] and 717-2 [36]. The measurements were taken at three locations of the tapping machine relative to the floor sample area

Table 3

Density and warping measurements of the tested specimens.

\begin{tabular}{|c|c|c|c|c|}
\hline Board & MDF & HDF & PE/Cork (50-50 wt.\%) & PP/Cork (50-50 wt.\%) \\
\hline Density $^{\mathrm{a}}\left(\mathrm{kg} \mathrm{m}^{-3}\right)$ & $822.7 \pm 2.7$ & $920.3 \pm 6.7$ & $1060.6 \pm 5.8$ & $1017.5 \pm 3.3$ \\
\hline Warping mean (mm) & $0.03 \pm 0.02$ & $0.04 \pm 0.03$ & $0.27 \pm 0.16$ & $0.31 \pm 0.11$ \\
\hline Board warping (\%) & $0.14 \pm 0.09$ & $0.18 \pm 0.14$ & $1.26 \pm 0.74$ & $1.44 \pm 0.51$ \\
\hline
\end{tabular}

a Density according to the standard ASTM D 792; \pm standard deviation values. 
of $2 \mathrm{~m}^{2}$ and five positions of microphone with to different lectures using one-third-octave bands, $100-4200 \mathrm{~Hz}$. The reduction of impact noise by floor covering on standard floor was determined according the equation:

$\Delta L=L_{n, 0}-L_{n}$

where $\Delta L$ is the reduction of impact sound pressure level, $L_{n, 0}$ is the normalized impact sound pressure level in the absence of floor covering and $L_{n}$ is the normalized impact sound pressure level with floor covering. The impact sound improvement index $\left(\Delta L_{w}\right)$ was determined according to the standard EN ISO 717-2 [36].

\section{Results and discussion}

\subsection{Dimensional stability tests}

The results from the water absorption and thickness swelling tests are shown in Figs. 2 and 3 respectively. In the first $6 \mathrm{~h}$ of immersion, the fibreboards samples absorbed $10.8 \pm 0.4 \%$ (HDF boards) and $14.8 \pm 0.8 \%$ (MDF boards). In the first $48 \mathrm{~h}$ of immersion the CPC samples absorbed less than $1 \%$ of water while the HDF and MDF ones absorbed $32.7 \pm 1.5 \%$ and $49.7 \pm 0.7 \%$ respectively. Moreover, after 11 days of immersion the maximum water absorption percentage of the developed CPC boards was $3.7 \pm 0.6 \%$ (for the PP/Cork) whereas the HDF and MDF boards absorbed, respectively, $77.9 \pm 2.4 \%$ and $125.6 \pm 0.9 \%$. These differences (more than 70\%) can be explained by the high amount of polyolefin (50 wt.\%) present in the CPC composition since, the non-polar polyolefin absorbs no or little water amount [25,37] and the inner volume accessible for water and oxygen is essentially zero [38]. Moreover, cork can also be considered a hydrophobic material. These results clearly indicate that CPC boards are more hydrophobic and absorb much less moisture than the hydrophilic MDF or HDF ones. These results also point out that CPC boards are more suitable to be used on environments where the materials are exposed to high moisture content than the control samples. Similar behaviour was observed for wood polyolefin composites developed using melt based technologies $[39,40]$. Like in wood composites, the water absorption in CPC materials occurs due to the presence of fine pores or lenticels in the cork particles (capillary absorption) and hydrogen bonding sites, or by some microcracks or gaps in the interface between cork particles and the polymeric matrix.

The thickness swelling results are shown in Fig. 3. The values observed for both fibreboards are considerably higher than the ones observed for the CPC boards. After an immersion period of $264 \mathrm{~h}$, the values of thickness swelling were, respectively, $0.5 \pm 0.2 \%$ and $0.8 \pm 0.3 \%$ for the PP/Cork and PE/Cork based composites, indicating good dimensional stability. On the contrary, for the same time period, the thickness swelling values of MDF and HDF were $85.3 \pm 1.5$ and $44.1 \pm 1.0$, respectively. Moreover,

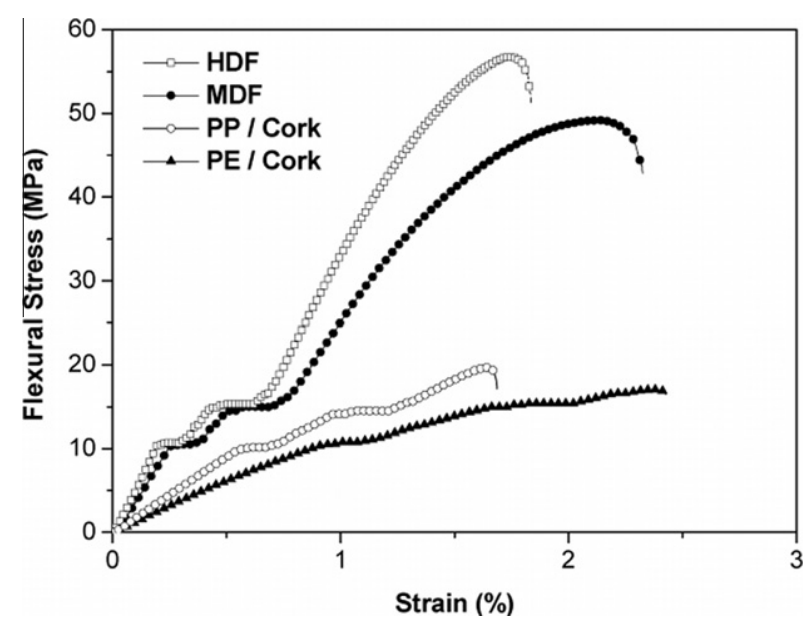

Fig. 4. Flexural stress-strain curves of the developed cork based composites and the fibreboard materials.

for the fibreboard specimens, thickness swelling values followed a similar trend to water absorption behaviour: thickness swelling values increased with the immersion time (Fig. 3). The CPC materials had a different behaviour: the thickness swelling was very low and the variation between the different immersion periods is almost insignificant. As in the water absorption behaviour, the low thickness swelling values of CPC materials can be an advantage for its application on the development and construction of several products, including its application as core material for laminated floor applications.

\subsection{Warping and density}

The density and warping values for the different materials are shown in Table 3 . The warping of the control fibreboards was near zero, with the mean value of $0.14 \%$ for MDF and $0.18 \%$ for the HDF. The developed CPC materials registered warping values of $1.26 \%$ for PE/Cork and $1.44 \%$ for PP/Cork. These values, although higher than ones registered for the fibreboards, can be considered small enough to classify the developed composites of high dimensional stability. The warping values were reduced with the addition of cork powder and are probably related with the crystallinity of the polymeric matrices (PP and PE) [38] where the presence of $50 \mathrm{wt} . \%$ of cork powder noticeably reduced the warping when it was applied the compression moulded process. Additionally, thicker areas cooled slower and part distortion could occur [41]. In this last case the warping can be reduced by increasing the cooling time during the compression moulding process.

The density of the composites ranges from $1017.5 \pm 3.3 \mathrm{~kg} \mathrm{~m}^{-3}$ for the PP/Cork composites to $1060.6 \pm 5.8 \mathrm{~kg} \mathrm{~m}^{-3}$ for the PE/Cork

Table 4

Flexural, impact and hardness properties of the cork based composites (50-50 wt.\%) and the commercial fibreboard materials.

\begin{tabular}{|c|c|c|c|c|c|}
\hline \multirow[t]{2}{*}{ Specimens } & \multicolumn{3}{|l|}{ Flexural } & \multirow{2}{*}{$\begin{array}{l}\text { Impact }^{\mathrm{b}} \\
\text { Strength }\left(\mathrm{kJ} / \mathrm{m}^{2}\right)\end{array}$} & \multirow{2}{*}{$\begin{array}{l}\text { Hardness } \\
\text { Shore D }\end{array}$} \\
\hline & Strength $^{\mathrm{a}}(\mathrm{MPa})$ & Modulus (GPa) & Strain at break ${ }^{\mathrm{a}}(\%)$ & & \\
\hline MDF & $49.6 \pm 0.9$ & $4.35 \pm 0.10$ & $2.30 \pm 0.14$ & $21.38 \pm 2.71$ & $50.8 \pm 0.6$ \\
\hline HDF & $58.9 \pm 3.7$ & $5.27 \pm 0.14$ & $1.96 \pm 0.20$ & $9.73 \pm 2.51$ & $50.2 \pm 0.6$ \\
\hline PP & $29.0 \pm 1.0$ & $1.03 \pm 0.03$ & $>10$ & $2.84 \pm 0.21$ & $45.9 \pm 1.4$ \\
\hline PP/Cork & $19.1 \pm 0.5$ & $1.75 \pm 0.10$ & $1.68 \pm 0.04$ & $5.53 \pm 0.24$ & $49.5 \pm 0.7$ \\
\hline HDPE & $19.5 \pm 1.2$ & $0.90 \pm 0.08$ & $>10$ & $4.44 \pm 0.20$ & $44.6 \pm 2.1$ \\
\hline PE/Cork & $17.1 \pm 0.7$ & $1.29 \pm 0.07$ & $2.46 \pm 0.10$ & $6.49 \pm 0.15$ & $47.9 \pm 1.3$ \\
\hline
\end{tabular}

\pm Standard deviation values.

a Maximum stress.

b Notched Charpy impact strength $\left(\mathrm{kJ} / \mathrm{m}^{2}\right)$. 
composites. These values are higher than the ones observed for the fibreboards. To understand this effect is important to note that the cork cell wall density has been estimated to be $1200 \mathrm{~kg} \mathrm{~m}^{-3}[3,4]$. Previous work using similar cork-polyolefin formulations [9] indicates a bulk density of the CPC pellets after pultrusion of around $590 \pm 11.4 \mathrm{~kg} \mathrm{~m}^{-3}$ to $602 \pm 13.4 \mathrm{~kg} \mathrm{~m}^{-3}$. The densification occurs in the compression moulding step due to the high applied compression force of $1.42 \mathrm{MPa}$. Studies on wood-polyolefin (50$50 \mathrm{wt} . \%$ ) composites regarding thermal and photo-oxidative stability indicate that the composite density controls the amount of air oxygen flowing into the pores of the composite matrix [38]. The higher density of a composite material blocks the access of oxygen and slows the oxidative degradation process.

\subsection{Mechanical tests}

Flexural, impact and hardness properties of the different materials were determined and the results are shown in Table 4. All results are expressed as means \pm standard deviation. The flexural strength obtained for the fibreboard samples were higher than the results obtained with the CPC materials (Fig. 4). The flexural strength and modulus of the control materials based on fibres where, respectively, $\sim 58.9 \mathrm{MPa}$ and $\sim 5.3 \mathrm{GPa}$ for the HDF and $\sim 49.6 \mathrm{MPa}$ and $\sim 4.4 \mathrm{GPa}$ for the MDF. The CPC materials presented modulus in the interval [1.8-1.3] GPa and strengths in the interval [19.1-17.1] MPa. The better mechanical performance of the CPC prepared with PP as matrix was expected since this polyolefin has better mechanical properties than the used PE. The lower values observed for the CPC samples can be related with the lack of interfacial adhesion and bonding between the matrix and the cork powder. Due to this, no stress transfer occurs during deformation resulting in low mechanical performance.

Regarding the flexural strain, the differences between the materials are not so evident. The samples from PE/Cork are the most ductile of the tested materials with $2.46 \%$ deformation, where the MDF presents a close value of $2.30 \%$. The high capacity of deformation of polyolefin is well known from the literature [42]. However, the addition of high percentages of cork (50 wt.\%) reduced the maximum strain to less than $3 \%$. The results are in accordance with other composite materials like wood-thermoplastic composites, where the increase of wood content increases the flexural modulus and decreases the flexural strength and maximum strain values of the composites $[1,43]$.

The purpose of the impact tests was to measure and compare the resilience, i.e. the energy absorption capacity of the different materials. As expected, the Charpy notched impact strength of fibreboard samples, mainly the ones from MDF, exhibited better mechanical properties when compared with the developed CPC
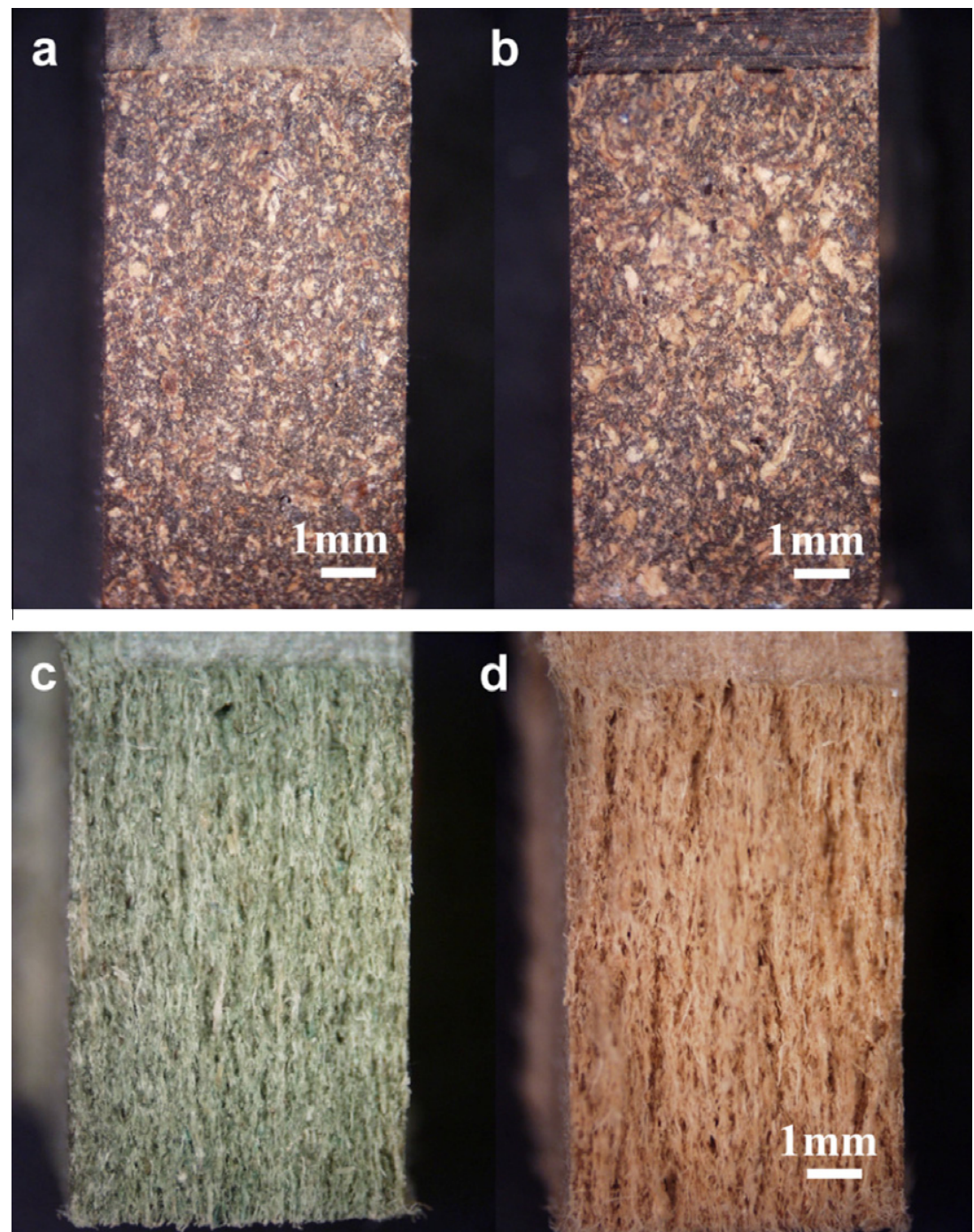

Fig. 5. Fracture surfaces of the specimens after Charpy notched impact tests with (a) PP/Cork (50-50 wt.\%), (b) PE/Cork (50-50 wt.\%), (c) HDF and (d) MDF. 
materials. The neat polymers present the lower value of impact strength of $4.4 \mathrm{~kJ} \mathrm{~m}^{-2}$ for HDPE and of $2.8 \mathrm{~kJ} \mathrm{~m}^{-2}$ for the PP. Nevertheless, the addition of $50 \mathrm{wt}$.\% of cork powder to the HDPE and PP matrices increased, respectively, $\sim 31 \%$ and $\sim 51 \%$ the impact strength, indicating that the presence of cork in the composite reinforces the energy absorption capacity. The cellular and elastic structure of cork $[3,4]$ can be an explanation for these results. Regarding the CPC materials, the energy absorption capacity of PP/Cork composite was $20 \%$ higher than in the PE/Cork composite. Since it was used the same amount of cork powder (50 wt.\%) and the processing conditions were similar, the higher MFI of PP contributed to a better dispersion of cork powder in the matrix and consequently increase in the absorption capacity. In terms of hardness, the specimens present similar values, around 49-51 Shore D, being the lower value corresponding to PE/cork and the high value to MDF material. When cork powder was added, hardness and the flexural modulus increased for both cases, probably due to the pultrusion process and the applied pressure of $1.42 \mathrm{MPa}$ during the compression moulding process.

\subsection{Morphology}

The fracture surface, after Charpy notched impact tests, of the studied materials was analysed by optical microscopy and the results presented in Fig. 5. For both CPC materials, it was observed a good dispersion of the cork powder particles in the polymeric matrix. In the case of the CPC with PP matrix it seems that cork distribution is more homogeneous. A possible explanation is the higher MFI value of the PP when compared with the MFI of HDPE (see Table 1). The fibreboard materials illustrate the well known fibrous aspect where the fibres are stacked like rows. This fibrous morphology is consistent with the previously reported results, namely the higher flexural mechanical performance and the ability of water to penetrate on these structures, inducing higher thickness swelling variations.

SEM micrographs from the same fracture surfaces are presented in Fig. 6. At low magnification (Fig. 6a and b) it is visible the high volume content of cork powder in the CPC materials. The cork powder/ polymer weight ratio used for the composites preparation was $50 \%$, but the volume this ratio is respectively, $86-14 \%$, respectively. In Fig. $6 \mathrm{c}$ is shown the morphology of the PE/Cork (50-50 wt.\%) material, where is possible to see the stretching of the PE between the cork cell walls. The same effect was observed for the CPC with PP matrix (Fig. 6d). Both images suggest that the surface of the cork particles interacted well with the polymeric matrix since voids or empty spaces between the two phases were not detected.

\subsection{Thermal properties}

The results of the termogravimetric analysis (TGA), conducted under air atmosphere, and the respective derivate (DTG) are shown in Fig. 7. Relevant data from all materials are summarized in Table 5 . The cork powder showed an initial region of mass loss between room temperature and $100{ }^{\circ} \mathrm{C}$ that is more significant for the two fibreboard materials corresponding to the elimination of water. In the case of the fibreboards the moisture content was higher, presenting at $100{ }^{\circ} \mathrm{C}$ values of around $6 \%$ comparing with $3.4 \%$ in cork. Nevertheless, as described in the literature, at $100{ }^{\circ} \mathrm{C}$ the moisture present in cork is not totally eliminated [14]. As expected, the current thermoplastics did not present residual moisture and, when combined with cork powder the CPC materials presented a weight loss in this region of $0.6-0.7 \%$.

Considering the data presented on Table 5 , the chemical degradation of cork starts at $258{ }^{\circ} \mathrm{C}$. This result suggests that the cork
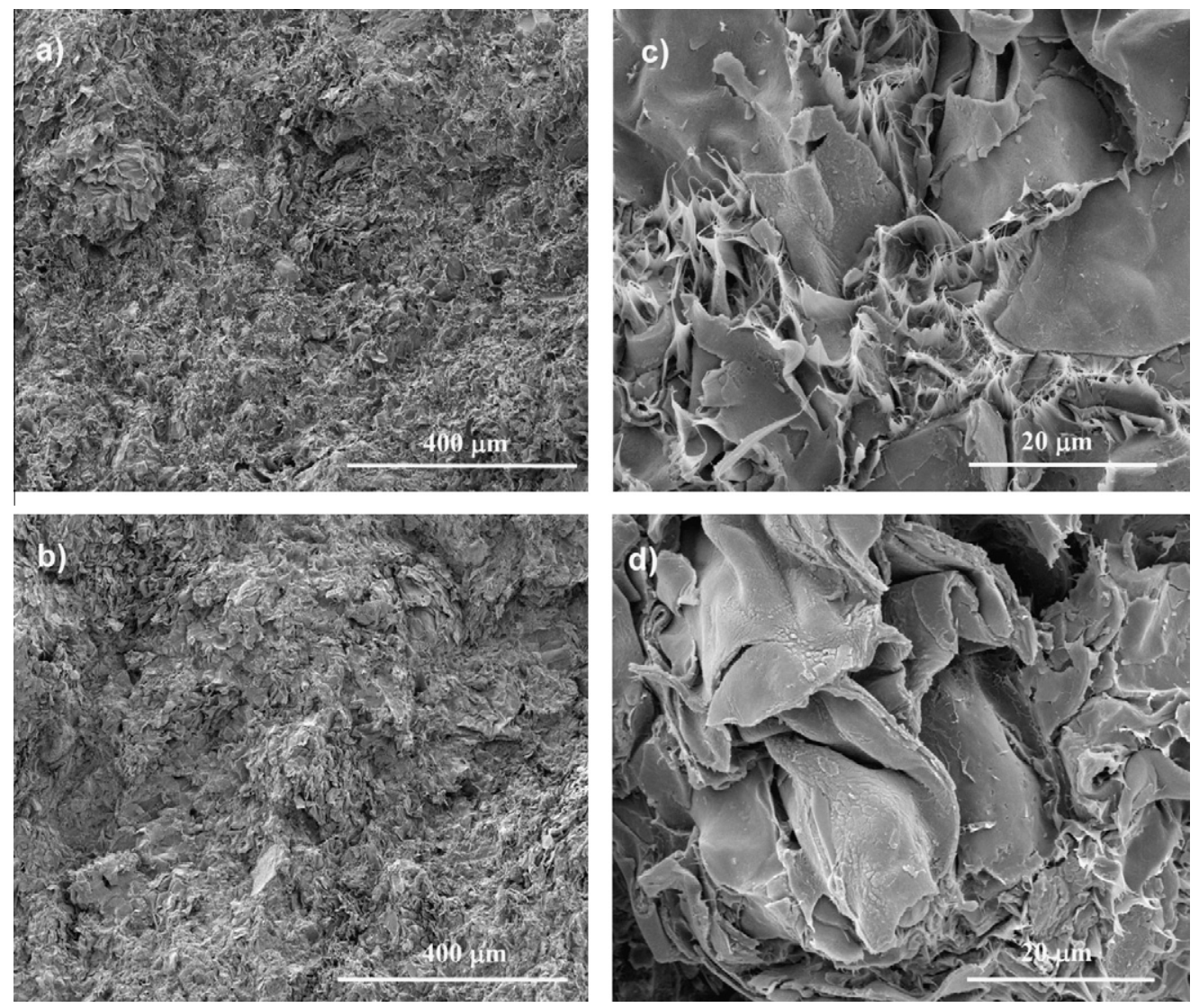

Fig. 6. Micrographs of the impact fracture surfaces of the (a and c) PE/Cork (50-50 wt.\%) and (b and d) PP/Cork (50-50 wt.\%) composites. 

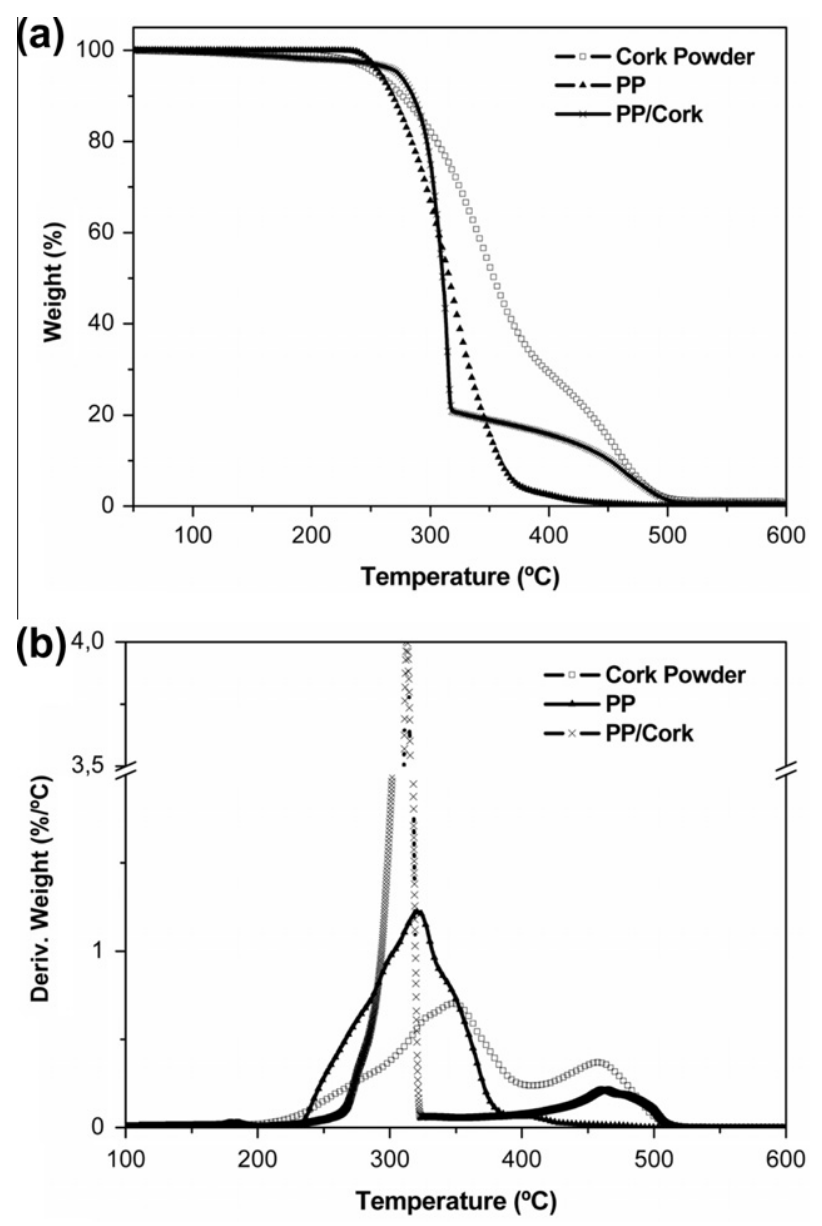

Fig. 7. TGA thermograms of the CPC composites with $\mathrm{PP}$ matrix and their components (a) and DTG curves of the thermograms (b) under air atmosphere.

powder can be processed with polymers having melting temperatures lower than this value, such as the used polyolefin's. However, other effects like colour change of cork, promoted by the tempera- ture and the processing time, must be considered. Additionally, results from Fig. 7 have shown that when cork powder is mixed with PP through melt-based technologies the thermal stability of the polymer increases.

Analysing DTG curve from cork powder, two maximum peaks were detected, one at $348{ }^{\circ} \mathrm{C}$ and other at $458^{\circ} \mathrm{C}$, being the first one of large intensity. The first peak corresponds to the two major constituents of cork (lignin and suberin fractions) and the second one can be attributed to suberin, the most thermal resistant component in cork. The polysaccharides composed by cellulose and hemicellulose have degradation temperatures in the range between $300{ }^{\circ} \mathrm{C}$ and $400^{\circ} \mathrm{C}$ [44].

The small values of weight loss $(0.76 \%)$ and the high onset temperature $\left(274^{\circ} \mathrm{C}\right.$ ) (see Table 5) obtained for HDPE are consistent with the presence of the thermal stabilizer. Other effect can be identified if the DTG values from both CPC are compared. In the case of PE/Cork the decomposition temperature peak $\left(T_{\max 1}\right)$ occurred at $341{ }^{\circ} \mathrm{C}$ with a weight loss of $28 \%$. For PP/Cork the $T_{\max 1}$ occurred earlier, at $313^{\circ} \mathrm{C}$ with higher weight loss of $59 \%$.

Both fibreboard materials showed multi-stepped degradation processes due to the presence of different species on their composition (data not shown). Literature described that the pyrolysis of wood begins with an early decomposition of hemicelluloses, followed by an early stage of pyrolysis of lignin, where the major decomposition temperature is normally attributed to the degradation of the cellulose [45].

Comparing all the tested materials, the most resistant is HDPE and PE/cork composite, since the used thermoplastic composition includes a thermal stabilizer. The fraction of the inorganic components, remaining from cork powder or from fibreboards, after exposed to $600{ }^{\circ} \mathrm{C}$, is minimal being $1 \%$ for cork powder and less than $0.6 \%$ for the fibreboards.

\subsection{Fire resistance}

The burning rates of the two different CPC and fibreboard materials were determined by single flame fire test (Table 6). The set-up procedure for testing the fire resistance is illustrated in Fig. 8a. In this test the flame takes contact at the edges of the specimen and start to burn in the vertical direction. When the neat HDPE was submitted to the flame (Fig. 8b) the material started dripping

Table 5

Thermal degradation characteristics of the tested specimens under air atmosphere.

\begin{tabular}{|c|c|c|c|c|c|}
\hline \multirow[t]{2}{*}{ Specimens } & \multicolumn{3}{|l|}{ TGA } & \multicolumn{2}{|l|}{ DTG } \\
\hline & Onset temp. $\left({ }^{\circ} \mathrm{C}\right)$ & Weight loss (\%) & Residual mass (\%) & $T_{\max 1}\left({ }^{\circ} \mathrm{C}\right)$ & $T_{\max 2}\left({ }^{\circ} \mathrm{C}\right)$ \\
\hline Cork Powder & 258 & 5.71 & 1.04 & 348 & 458 \\
\hline $\mathrm{PP}$ & 265 & 3.88 & 0.12 & 322 & - \\
\hline HDPE & 274 & 0.76 & 0.11 & 358 & 451 \\
\hline HDF & 275 & 13.80 & 0.59 & 318 & 455 \\
\hline MDF & 265 & 10.29 & 0.23 & 319 & 446 \\
\hline PP/Cork & 289 & 12.21 & 0.70 & 313 & 464 \\
\hline PE/Cork & 282 & 5.81 & 0.70 & 341 & $416 / 482$ \\
\hline
\end{tabular}

Table 6

Fire resistance test results for the tested specimens.

\begin{tabular}{|c|c|c|c|c|c|}
\hline \multirow[t]{2}{*}{ Specimen } & \multirow[t]{2}{*}{ Inflammability time (s) } & \multicolumn{3}{|c|}{ Burning dimensions } & \multirow{2}{*}{$\begin{array}{l}\text { Fire resistance } \\
\text { Euroclasse }^{\mathrm{a}}\end{array}$} \\
\hline & & Length (mm) & Width (mm) & Depth (mm) & \\
\hline MDF & $15-20$ & $17.0 \pm 1.4$ & $20.3 \pm 0.5$ & 0 & $\mathrm{E}$ \\
\hline $\mathrm{HDF}$ & $15-20$ & $20.0 \pm 0.1$ & $18.3 \pm 0.5$ & 0 & $\mathrm{E}$ \\
\hline PE/Cork & $15-20$ & $37.3 \pm 4.0$ & $38.3 \pm 3.3$ & 0 & $\mathrm{E}$ \\
\hline PP/Cork & $15-20$ & $39.3 \pm 1.9$ & $38.7 \pm 3.5$ & 0 & $\mathrm{E}$ \\
\hline
\end{tabular}

\footnotetext{
${ }^{a}$ Fire resistance classification according the standard fire test of building materials BS EN 13501-1.
} 


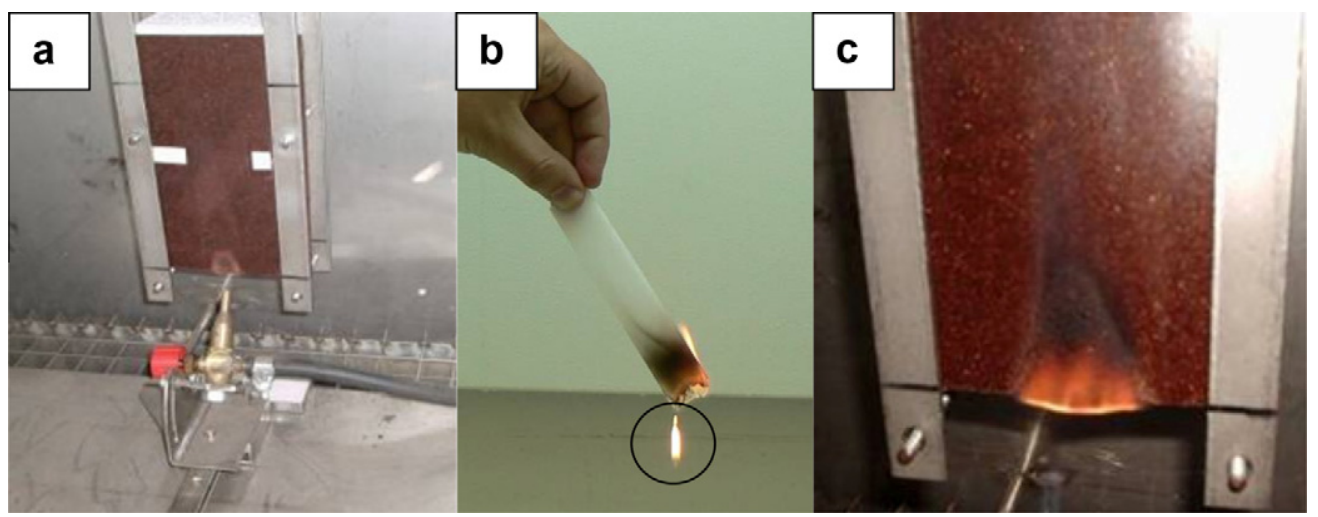

Fig. 8. System for testing the fire resistance (a) behaviour of PE to the flame (b) and CPC behaviour after fire test of the PE/Cork (50-50 wt.\%) specimen (c).

after a few seconds and the integrity of the material was completely lost. The addition of $50 \mathrm{wt} . \%$ of cork powder to the polymeric matrix improved such behaviour and the composites maintained the integrity during the whole test. The presence of cork powder sustained the polymeric phase and acted as a fire retardant improving the performance of the composites. This behaviour reinforces and agrees with the results obtained with the TGA analysis. The fire resistance tests conducted on the fibreboards revealed that these materials possess a self-extinguishing behaviour after removing the flame. This behaviour was not observed for the composite materials since the flame does not extinguish eventually (Fig. 8c). Small differences in the burnt area were found, being the fibreboard materials the ones with lower values. Between the two CPC composites no relevant differences were found. In our opinion, the effect of the cork powder is higher and overlaps with the thermal stabilizer in HDPE.

The results from the fire resistance tests (Table 6) indicated that all tested specimens possess a good behaviour regarding fire resistance since all the tested materials had a classification of $E$.

\subsection{Acoustic tests}

By measuring the impact sound pressure level reduction, $\Delta L$, of the different board materials (Fig. 9), it was possible to compare, as a function of the frequency, the behaviour of the different board systems. As expected, the sound pressure level reduction increased as the frequency increased. Moreover, it was found that, at high

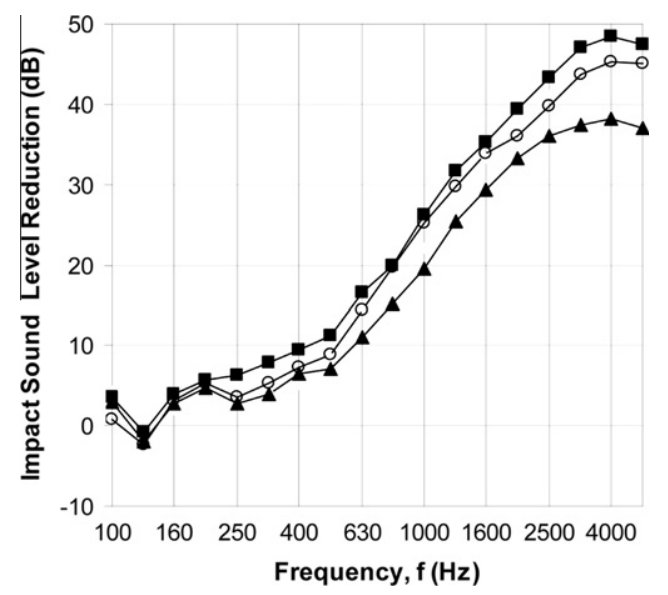

Fig. 9. Impact sound reduction $\Delta L$ vs. frequency due to installation of the tested materials: ( $\bigcirc)$ MDF; ( $\Delta$ ) HDF and (ם) PE/Cork (50-50 wt.\%). Experimental results in the $1 / 3$ octave band frequency domain. frequencies, the cork-based composite showed better behaviour when compared with the commercially fibreboard materials.

The impact sound attenuation index $\left(\Delta L_{w}\right)$, is useful for a direct comparison of the reduction in impact noise transmission by the floor coverings. The $\Delta L_{w}$ values ranged from $18 \mathrm{~dB}$ (for MDF and HDF floor covering) to $20 \mathrm{~dB}$ for the (PE/Cork) floor covering. The obtained values are in the same range of values in the literature $[46,47]$. The cellular and corrugated structure of cork together with the high volume percentage of this natural material ( $~ 86 \%)$ can be the key for the superior $\Delta L_{w}$ value of $20 \mathrm{~dB}$.

The board density, which is described as a parameter affecting the sound transmission properties, can explain the improved behaviour of the MDF compared with HDF in terms of impact sound reduction especially for medium and high frequencies. In the literature is also pointed that the use of urea-formaldehyde (UF) resin in the fibre based materials can also contribute to additional improvement on the acoustic properties [28].

In the present work the $\Delta L_{w}$ of the all tested floor coverings was influenced by the use of silicon glue to fix the cork underlay to the boards. The silicon might also improve the soundproof properties providing a small increase on the impact sound attenuation index values for all tested boards. The commercial fibreboard tested materials also present a small percentage of UF resin.

\section{Conclusions}

The purpose of this study was to compare two different CPC materials with two commercially available fibreboard materials and detect its advantages and drawbacks. The obtained results showed the potential of this natural-based product on the development of composites with improved characteristics namely, low water absorption, fire resistance, impact resistance and insulation properties.

Both CPC materials compounded by pultrusion and further processed by compression moulding presented a good dispersion and distribution of the cork powder particles in the thermoplastic matrix. Moreover, the CPCs reveal good dimensional stability with low water absorption in comparison with fibreboard materials.

The mechanical properties of the fibre-based materials were considerably superior compared with the ones from the CPCs. With the addition of cork ( $50 \mathrm{wt} . \%)$, the flexural strength and strain were considerably reduced and the modulus was improved in both cases. The impact resistance tests confirm that the addition of cork powder improved the energy absorption capacity of the used polyolefin's.

The presence of cork presents the advantage to act as fire retardant in the thermoplastic composite materials. The acoustic behaviour revealed that CPC materials possess improved impact sound 
insulation properties, low water absorption and reduced thickness swelling. These materials proved to be good candidates to be used as underlay materials on floor applications. The developed cork composite materials present some promising properties, although reinforcement strategies to reach to higher stiffness and strength could be needed for specific applications.

\section{Acknowledgments}

The work was performed within the project of Corticeira Amorim SGPS on the development of new products based in/with cork. We gratefully acknowledge to Amorim Revestimentos S.A. for the cork powder. The support of Pallmann GmbH for the polyolefin's and the pultrusion system, Professor Carvalho A.P.O. and Eng. Marques P. from Dept. of Civil Eng., University of Porto (FEUP) for the support on the acoustic tests are also gratefully acknowledged.

\section{References}

[1] Bledzki AK, Reihmane S, Gassan J. Thermoplastics reinforced with wood fillers: a literature review. Polym-Plast Technol Eng 1998;37(4):451-68.

[2] Rowell R. Challenges in biomass - thermoplastic composites. J Polym Environ 2008;15(4):229-35

[3] Gibson LJ. Cellular solids: structure and properties. 2nd ed. Cambridge: Cambridge University Press; 1997.

[4] Silva SP, Sabino MA, Fernandes EM, Correlo VM, Boesel LF, Reis RL. Cork: properties, capabilities and applications. Int Mater Rev 2005;50(6):345-65.

[5] Matos MJ, Simplício MH. Innovation and sustainability in mechanical design through materials selection. Mater Des 2004;27:74-8.

[6] Fernandes EM, Silva VM, Chagas JAM, Reis RL. Cork-polymer composite (CPC) materials and processes to obtain the same. WO2009072914-A1, Amorim Revestimentos, SA; 2009.

[7] Gil L. Cork composites: a review. Mater Des 2009;2:776-89.

[8] Cosby SA, Kelly M, Van WB. Silicone-cork ablative material. EP 1482163 A2. United Technologies Corp.; 2005.

[9] Fernandes EM, Correlo VM, Chagas JAM, Mano JF, Reis RL. Cork based composites using polyolefin's as matrix: morphology and mechanical performance. Compos Sci Technol 2010;70:2310-8.

[10] Pereira H. Cork: biology, production and uses. Amsterdam: Elsevier; 2007.

[11] Pereira H, Rosa ME, Fortes MA. The cellular structure of cork from Quercus suber L.. Iawa Bull 1987;8(3):213-8.

[12] Gibson LJ, Easterling KE, Ashby MF. The structure and mechanics of cork. Proc Roy Soc Lond A Mater 1981;A 377:99-117.

[13] Gil L, Cork Moiteiro C. Ullmann's encyclopedia of industrial chemistry. Weinheim: Willey-VCH; 2002

[14] Rosa ME, Fortes MA. Thermogravimetric analysis of cork. J Mater Sci Lett 1988;7(10):1064-5.

[15] Rosa ME, Fortes MA. Temperature-induced alterations of the structure and mechanical-properties of cork. Mater Sci Eng 1988;100:69-78.

[16] Pereira H. The thermochemical degradation of cork. Wood Sci Technol 1992;26(4):259-69.

[17] Neto CP, Rocha J, Gil A, Cordeiro NMA, Esculcas AP, Rocha S, et al. C-13 solidstate nuclear-magnetic-resonance and Fourier-transform infrared studies of the thermal-decomposition of cork. Solid State Nucl Mag 1995;4(3):143-51.

[18] Varea S, García-Vallejo MC, Cadahía E, Simón BFd. Polyphenols susceptible to migrate from cork stoppers to wine. Eur Food Res Technol 2001;213:56-61.

[19] Bento MFS, Cunha MA, Moutinho AMC, Pereira H, Fortes MA. A massspectrometry study of thermal-dissociation of cork. Int J Mass Spectrom Ion Process 1992;112(2-3):191-204.

[20] Gil L. Cork powder waste: an overview. Biomass Bioenergy 1997;13(1-2): 59-61.
[21] Barlow CY, Ashby MF. Cork dust composites. In: Proceedings of the Riso international symposium on metallurgy and materials science; 1989.

[22] Abdallah FB, Cheikh RB, Baklouti M, Denchev Z, Cunha AM. Effect of surface treatment in cork reinforced composites. J Polym Res 2009;17(4):519-28.

[23] Mano JF. The viscoelastic properties of cork. J Mater Sci 2002;37(2):257-63.

[24] Bledzki AK, Gassan J, Theis S. Wood-filled thermoplastic composites. Mech Compos Mater 1998;34(6):563-8.

[25] Espert A, Vilaplana F, Karlsson S. Comparison of water absorption in natural cellulosic fibres from wood and one-year crops in polypropylene composites and its influence on their mechanical properties. Compos Part A - Appl Sci 2004;35(11):1267-76.

[26] Li X, Li Y, Zhong Z, Wang D, Ratto JA, Sheng K, et al. Mechanical and water soaking properties of medium density fiberboard with wood fiber and soybean protein adhesive. Bioresource Technol 2009;100(14):3556-62.

[27] Singh B, Gupta M, Verma A. Mechanical behaviour of particulate hybrid composite laminates as potential building materials. Construct Build Mater 1995;9(1):39-44

[28] Hashim R, Sulaiman O, Kumar RN, Tamyez PF, Murphy RJ, Ali Z. Physical and mechanical properties of flame retardant urea formaldehyde medium density fiberboard. J Mater Process Technol 2009;209(2):635-40.

[29] ASTM D570-98. Standard test method for water absorption of plastics. West Conshohocken: ASTM International; 1998.

[30] ASTM D 792-00. Standard test methods for density and specific gravity (relative density) of plastics by displacement; 2000.

[31] ISO 178. Plastics - determination of flexural properties; 2001.

[32] ISO 179-1. Determination of Charpy impact properties-Part 1: Noninstrumented impact test; 2000.

[33] ISO 11925-2. Reaction to fire tests - ignitability of building products subjected to direct impingement of flame - Part 2: Single-flame source test; 2002.

[34] BS EN ISO 13501-1. Fire classification of construction products and building elements. Classification using test data from reaction to fire tests; 2002.

[35] ISO 140-8. Acoustics - measurement of sound insulation in buildings and of building elements - Part 8: Laboratory measurements of the reduction of transmitted impact noise by floor coverings on a heavyweight standard floor; 1997.

[36] ISO 717-2. Acoustics - Rating of sound insulation in buildings and of building elements - Part 2: Impact sound insulation; 1996.

[37] Shi SQ, Gardner DJ. Hygroscopic thickness swelling rate of compression molded wood fiberboard and wood fiber/polymer composites. Compos Part A - Appl Sci 2006;37(9):1276-85.

[38] Klyosov AA. Wood-plastic composites. Hoboken, New Jersey: John Wiley \& Sons, Inc.; 2007.

[39] Ichazo MN, Albano C, Gonzalez J, Perera R, Candal MV. Polypropylene/wood flour composites: treatments and properties. Compos Struct 2001;54(2-3): 207-14.

[40] Yang HS, Kim HJ, Park HJ, Lee BJ, Hwang TS. Water absorption behavior and mechanical properties of lignocellulosic filler-polyolefin bio-composites. Compos Struct 2006;72(4):429-37.

[41] Wakeman MD, Rudd CD, Anthony K, Carl Z. Compression molding of thermoplastic composites. In: Comprehensive composite materials. Oxford: Pergamon; 2000. p. 915-63.

[42] Mourad A-HI. Thermo-mechanical characteristics of thermally aged polyethylene/polypropylene blends. Mater Des 2010;31(2):918-29.

[43] Adhikary KB, Pang SS, Staiger MP. Dimensional stability and mechanical behaviour of wood-plastic composites based on recycled and virgin highdensity polyethylene (HDPE). Compos Part B - Eng 2008;39(5):807-15.

[44] Averous L, Boquillon N. Biocomposites based on plasticized starch: thermal and mechanical behaviours. Carbohydr Polym 2004:56(2):111-22.

[45] Lee HL, Chen GC, Rowell RM. Thermal properties of wood reacted with a phosphorus pentoxide-amine system. J Appl Polym Sci 2004;91(4):2465-81.

[46] Carvalho APO, Vafiadis C, Borrego $\mathrm{H}$. The use of agglomerated cork as underlay for improvement of impact sound insulation in buildings. In: 137th ASA meeting \& 2nd forum acusticum, Berlin; 1999.

[47] Rodrigues RC, Carvalho APO. Natural vegetal fibbers as a new resilient layer for floating floors. In: Proceedings of 5th euronoise, Naples, Italy; 2003. 